\title{
Conduta clínica para tratamento de dentes supranumerários: Relato de caso clínico
}

\author{
Clinical conduct for treating supranumerary teeth: A case report \\ Conducta clínica para el tratamiento de dientes supranumerarios: Reporte de un caso
}

Recebido: 05/05/2021 | Revisado: 12/05/2021 | Aceito: 14/05/2021 | Publicado: 30/05/2021

\author{
Brunna Mendes Araújo \\ ORCID: https://orcid.org/0000-0002-2683-0905 \\ Faculdade Patos de Minas, Brasil \\ E-mail: brunnaamendess@hotmail.com \\ Rafaela Ramirez Morato \\ ORCID: https://orcid.org/0000-0003-3921-1668 \\ Faculdade Patos de Minas, Brasil \\ E-mail: rafaela_moratoo3m@hotmail.com \\ Marcelo Dias Moreira de Assis Costa \\ ORCID: https://orcid.org/0000-0001-9148-3674 \\ Universidade Federal de Uberlândia, Brasil \\ E-mail: marcelodmac@yahoo.com.br \\ Lia Dietrich \\ ORCID: https://orcid.org/0000-0001-7887-8591 \\ Clínica Privada, Brasil \\ E-maildietrichlia.ld@gmail.com \\ Victor da Mota Martins \\ ORCID: https://orcid.org/0000-0001-6631-6161 \\ Faculdade Patos de Minas, Brasil \\ E-mail: victor.martins@faculdadepatosdeminas.edu.br \\ Mayra Maria Coury de França \\ ORCID: https://orcid.org/0000-0002-9395-6823 \\ Faculdade Patos de Minas, Brasil \\ E-mail: mayra.franca@faculdadepatosdeminas.edu.br
}

\begin{abstract}
Resumo
Os dentes supranumerários (DS) são alterações no desenvolvimento dentário classificadas como uma anomalia de número, a mais comumente relatada nas clínicas odontológicas. O presente artigo tem como objetivo fazer uma revisão em literaturas e relatar através de um caso clínico, as etapas do procedimento cirúrgico, informações relevantes sobre o diagnóstico e tratamento de dentes supranumerários. O paciente E.D.L., do sexo masculino, 20 anos de idade, compareceu à Policlínica da Faculdade de Patos de Minas - MG, com a queixa principal de incômodo nos dentes supranumerários, que totalizavam dez elementos. O trabalho foi submetido ao Comitê de Ética e Pesquisa (CEP) com seres humanos da Faculdade Patos de Minas (FPM), sob o número de parecer 4.473.826. Foi realizada toda anamnese, seguida de protocolo fotográfico, assepsia e antissepsia e anestesia localizada. Foi realizada uma incisão sulcular com descolamento do periósteo, seguida de luxação com alavancas reta e curva e auxílio de fórceps para remoção dos dentes em oclusão, curetagem do alvéolo com cureta de Lucas e irrigação com soro fisiológico estéril. Foi necessária a odontosecção com broca Zecria nos dentes inclusos. O retalho foi posicionado e suturado com fio de sutura tipo nylon. Foram aguardados 10 dias para a remoção da sutura. Após o diagnóstico conclusivo e a determinação cirúrgica, o paciente relatado recebeu tratamento indicado para o seu caso com sucesso, removendo seus dentes supranumerários e garantindo a sua saúde bucal; demonstrando a pertinência do diagnóstico rápido, completo e da individualização da propedêutica nesses casos, a fim de evitar complicações futuras e melhorar a autoestima e a sociabilização do paciente. Palavras-chave: Dente supranumerários; Cirurgia bucal; Assistência odontológica.
\end{abstract}

\begin{abstract}
Supernumerary teeth (ST) are changes of the dental development classified as a number anomaly, the most common reported in the dental clinics. This article aims to review in literature and to report through a clinical case the stages of the surgical procedure, relevant information on the diagnosis and treatment of supernumerary teeth as well. Patient E.D.L., a male one, 20 years old, attended the Polyclinic of Patos de Minas MG College, and the main complaint was the nuisance with supernumerary teeth in a total of ten elements. The work was submitted to the Research Ethics Committe (REC) with human beings from Faculdade Patos de Minas (FPM) under the number of opinion: 4,473,826. Anamnesis was performed, followed by a photographic protocol, asepsis, antisepsis and local anesthesia. A sulcular incision was made with detachment of the periosteum, followed by dislocation with straight and curved levers and forceps to remove occlusion teeth, the curettage of the alveolus with Lucas curette and irrigation with sterile saline. It was necessary to have an odonto-section with a Zecria drill on the included teeth. The flap was positioned and sutured
\end{abstract}


with nylon suture. Ten days were waited for the suture to be removed. After conclusive diagnosis and surgical determination, the reported patient received treatment indicated for his case successfully, by removing his supernumerary teeth and guaranteeing his oral health, demonstrating the relevance of rapid and complet diagnosis, and also the individualization of propaedeutics in these cases, in order to avoid future complications and to improve the patient's self-esteem and socialization.

Keywords: Supernumerary tooth; Oral surgery; Dental care.

\section{Resumen}

Los dientes supernumerarios (DS) son cambios en el desarrollo dental clasificados como anomalía numérica, la más común reportada en la clínica dental. Este artículo tiene como objetivo revisar la literatura y reportar, a través de un caso clínico, etapas del procedimiento quirúrgico, información relevante sobre el diagnóstico y tratamiento de los dientes supernumerarios. Paciente E.D.L., varón, 20 años, acudió al Policlínico de la Facultad de Patos de Minas-MG, el principal síntoma fue el malestar con dientes supernumerarios totalizando diez elementos. El trabajo fue presentado al Comité de Ética e Investigación (CEP) con seres humanos de la Faculdade Patos de Minas (FPM) bajo el número de opinión: 4.473.826. Se realizó anamnesis, seguida de protocolo fotográfico, asepsia y antisepsia y anestesia localizada. Se realizó una incisión sulcular con desprendimiento del periostio, seguida de luxación con palancas rectas y curvas y la ayuda de fórceps para remover los dientes oclusivos, legrado del alvéolo con cureta Lucas e irrigación con suero fisiológico estéril. Era necesario tener una odonto-sección con un taladro Zecria en los dientes incluidos. El colgajo se colocó y se suturó con sutura de nailon. Se esperaron diez días para retirar la sutura. Luego de diagnóstico concluyente y determinación quirúrgica, el paciente reportado recibió el tratamiento indicado para su caso con éxito, removiendo sus dientes supernumerarios y garantizando su salud bucal, demostrando la relevancia del diagnóstico rápido, completo e individualización de la propedéutica en estos casos, a fin de evitar futuras complicaciones. y mejorar la autoestima y la socialización del paciente.

Palabras clave: Diente supernumerario; Cirugía bucal; Atención odontológica.

\section{Introdução}

Os dentes supranumerários ou extranumerários são alterações de desenvolvimento dentário, classificadas como uma anomalia de número, sendo comum na clínica odontológica1. Caracteriza-se pelo aparecimento de dentes extras na cavidade bucal (Lodi, Rodrigues, \& Angeloni, 2017; Stringhini Junior, Stang, \& Oliveira, 2015). A dentição é supranumerária quando o número de dentes é superior a 20 na dentição decídua e 32 na dentição permanente (Alencar, Sorares, Santos, \& Silva, 2016; Loreto, Kelmer, \& Oliveira, 2015).

No século 19 ocorreu o primeiro relato registrado na literatura, de um caso semelhante em um homem de 17 anos. A partir desse cenário, as publicações são recorrentes com essa temática (Tuner, 1877). Já fora relatado também que essa condição é mais comum no sexo masculino. Ademais, o mesiodens representa $80 \%$ dos supranuméricos, e é localizado na maxila entre os incisivos centrais superiores (Anegundi et al, 2014; Sykaras, 1975; Santos, Diniz, Matos, Veloso, \& Sá, 2019). Algumas teorias têm como embasamento a existência de uma hiperatividade da lâmina dentária ou dissertam que a hiperdontia decorre de uma dicotomia do broto dentário. Entretanto, ainda não se chegou a um consenso do processo etiológico, sendo denotado que a condição advém de um conjunto multifatorial complexo (Dias, Hagedom, Maffezzolli, Silva, \& Alves, 2019; Moura et al, 2013, Tuna, Kurklu, Gencay, Ak, 2013).

Além disso, os dentes supranumerários também podem estar associados a pacientes que possuem diagnósticos de síndromes e transtornos de desenvolvimento (Boehn, 1963; Silva, Hipólito, Vincentin, Goya, \& Junior, 2018), como síndrome de Gardner, disostose cleidocraniana, fendas palatinas e fissuras labiais7. Alguns trabalhos relatam que o diagnóstico de indivíduos com dentes supranumerários é feito em atendimentos de rotina clínica e quando exames radiográficos são solicitados (Hattab, 2014; Kim, Ruprecht, Jeon, \& Park, 2003; Oliveira, PEreira, Ferreira, Paiva, \& Fraiz, 2013; Araújo Junior, 2021).

O diagnóstico precoce desta condição pode prevenir complicações adicionais ao sistema estomatognático, tais como: apinhamento dentário, impactação de dentes permanentes, retardo na erupção, deslocamento ou rotação dentária, formação de diastemas, desenvolvimento de lesões císticas, reabsorção radicular de dentes adjacentes, perda de espaço e irrompimento de dentes supranumerários na cavidade nasal (Agrawal, 2012, Nunes et al, 2017, Primo, Wilhelm, \& Bastos, 1997).

São possíveis duas linhas de tratamento: a primeira seria a extração dentária precoce, prevenindo danos aos dentes 
permanentes adjacentes; a segunda seria a realização do tratamento conservador, que consiste em mantê-los em observação enquanto a patologia não causa interferência estética ou funcional, mantendo a erupção dos dentes relacionados satisfatória (Moura et al, 2013, Shah, Patel, Ranadheer, \& Shoba, 2015; Silva, 2020).

Diante dessa perspectiva, este trabalho tem como objetivo revisar na literatura e relatar através de um caso clínico, etapas do procedimento cirúrgico, informações relevantes sobre o diagnóstico e tratamento de dentes supranumerários; produzindo assim, conhecimento que seja de relevância social e que possa se tornar embasamento para condutas odontológicas e de fins de pesquisa.

\section{Metodologia}

Este estudo é de caráter qualitativo e descritivo, e foi realizado por meio de um relato de um caso clínico de um paciente da Policlínica da Faculdade de Patos de Minas (FPM), no Município de Patos de Minas - Minas Gerais (Pereira, 2018).

Foram utilizados para busca de dados, informações e literaturas relacionadas, a biblioteca local da Faculdade Patos de Minas e os repositórios on-line, localizados pelo mecanismo de busca do Google Acadêmico, Scielo, PubMed e LILACS. Foram usadas as palavras-chave "dentes supranumerários", "anomalia dentária de número", "anomalia congênita de desenvolvimento" em português e em inglês para a pesquisa. Para alcançar os objetivos propostos fora descrita toda a anamnese, exame extrabucal e intrabucal, exame clínico, exame radiográfico e também toda a técnica aplicada para a remoção cirúrgica dos dentes supranumerários e o pós-operatório do paciente.

Os dados coletados no trabalho não identificaram o paciente, assim como o mesmo poderia desistir da participação no estudo a qualquer momento. O paciente foi informado sobre todos os direitos através do Termo de Consentimento Livre e Esclarecido (TCLE) e o assinou. O presente artigo foi submetido ao Comitê de Ética em Pesquisa via Plataforma Brasil e aprovado sob o número de parecer 4.473.826.

O mesmo obedece à legislação nacional vigente, para realização da pesquisa envolvendo seres humanos, conforme a Resolução 466/2012 do Conselho Nacional de Saúde (CNS).

\section{Descrição do Caso Clínico}

O paciente descrito por E.D.L., do sexo masculino, 20 anos, compareceu à Policlínica da Faculdade de Odontologia de uma cidade no interior de Minas Gerais, para avaliação clínica. Durante anamnese, o mesmo relatou que nunca havia realizado tratamento odontológico e a queixa principal era o incômodo com os dentes supranumerários. Negava ser portador de doenças prévias e havia realizado procedimento cirúrgico no joelho. Não sentia dores nos dentes, mas relatou sangramento gengival esporádico e estalidos da articulação temporomandibular. Declarou realizar a higiene bucal através da escovação com pasta dental duas vezes ao dia, e às vezes, também com uso de fio dental e enxaguante bucal. Ao realizar o exame físico intra oral, foi detectado que haviam lesões de cárie em superfície oclusal dos dentes 16, 17, 18, 26, 27,28 e 47; desgastes incisais nos dentes $31,32,41,42,43$ e 44; restaurações de resina nos dentes $36,37,38$ e 46; e presença de supranumerários associados aos dentes 24, 25, 34, 35, 36; totalizando seis elementos supra numerários em oclusāo.

Fora realizado o tratamento das lesões cariosas em regime ambulatorial e solicitada uma radiografia panorâmica (Figura 1). A radiografia realizada diagnosticou a presença de elementos supranumerários em formação à distal do elemento 18, dois em formação entre os elementos 15 e 14, um elemento sobreposto à porção radicular do 13, possível elemento em coroa do 24 , supranumerário em formação entre o 24 e 25, à distal do 28 e dois impactados sobrepostos à porção radicular do 45. Após análise da radiografia, conclui-se em laudo a necessidade de uma avaliação do histórico de hereditariedade e/ou alterações sistêmicas no paciente, além de uma tomografia computadorizada por feixe cônico para precisão no diagnóstico de mais dentes. 
Research, Society and Development, v. 10, n. 6, e31110615807, 2021

(CC BY 4.0) | ISSN 2525-3409 | DOI: http://dx.doi.org/10.33448/rsd-v10i6.15807

Figura 1. Radiografia panorâmica.

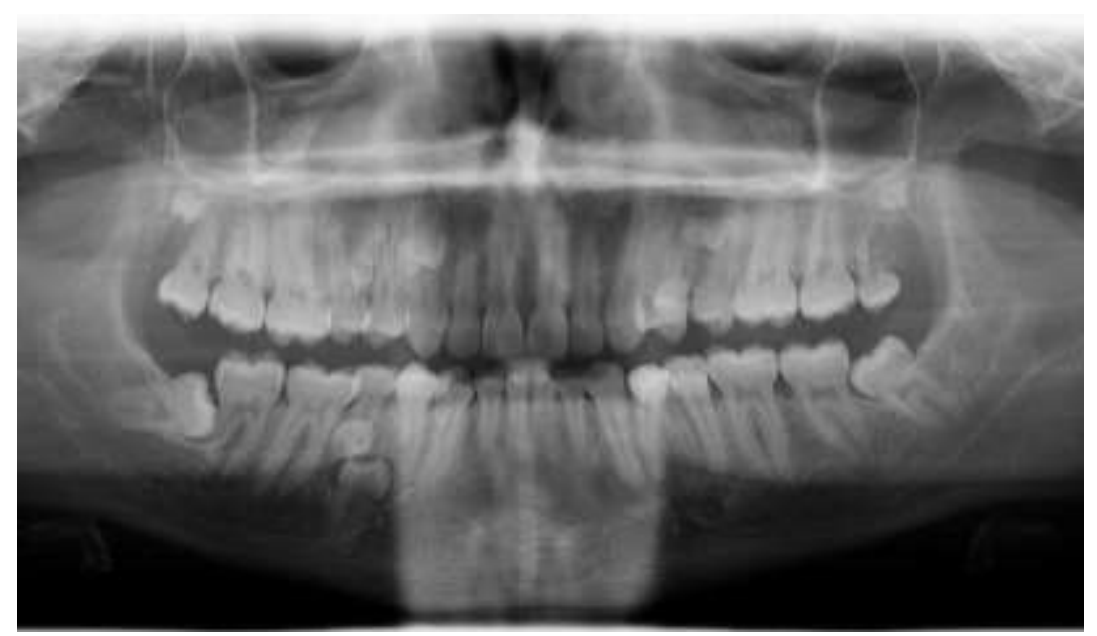

Fonte: Prontuário do paciente.

Em nova consulta, E. D. L. relatou que seus dois irmãos também sofrem com dentes extranumerários e novamente negou qualquer doença prévia. Solicitou-se uma tomografia (Figura 2) para melhor avaliação e planejamento do tratamento. 
Figura 2 - imagens de tomografia.

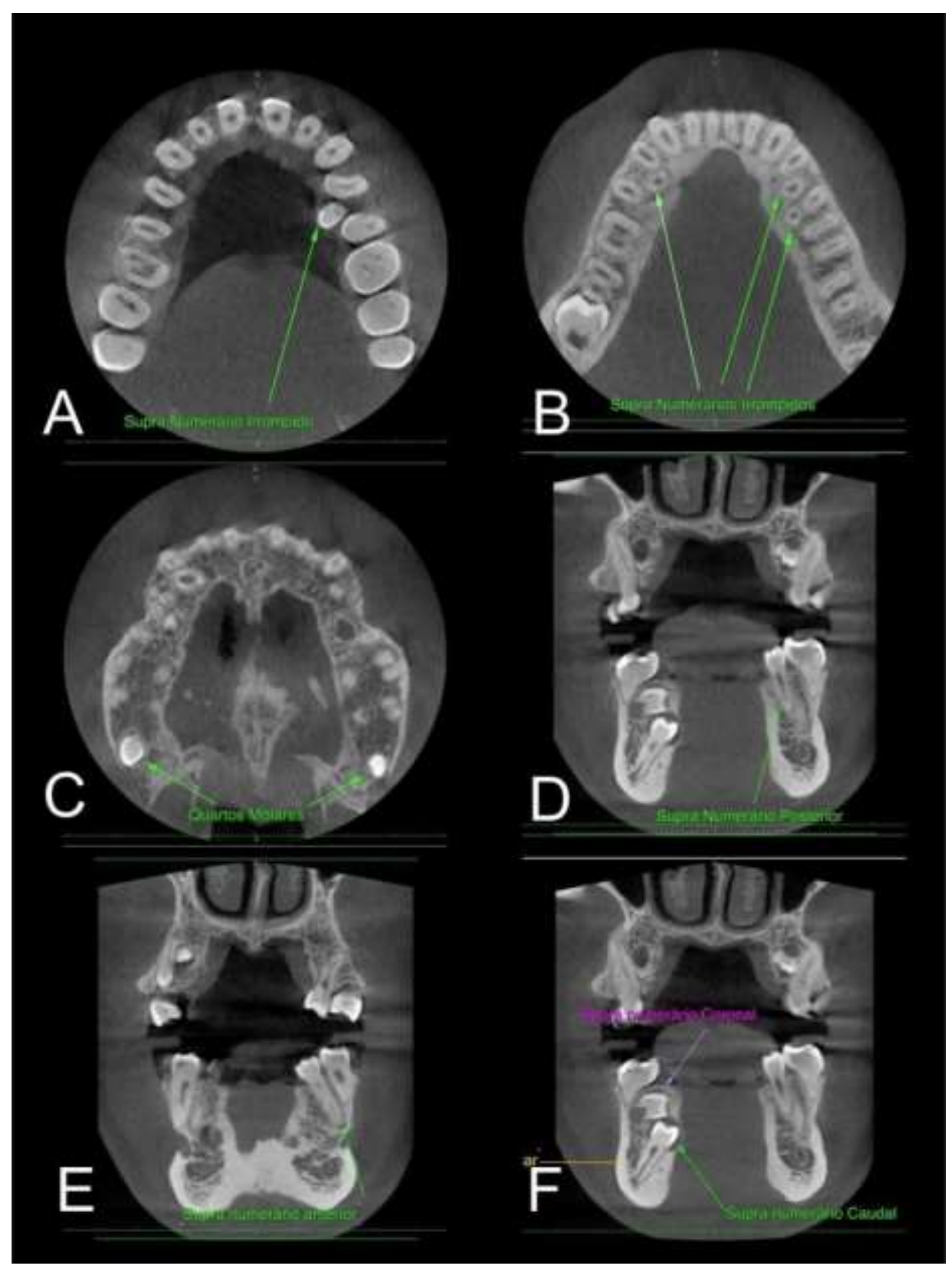

Fonte: Prontuário do paciente.

A: corte axial demonstrando elemento supranumerário mandibular irrompido; B: corte axial demonstrando elementos supranumerários mandibulares irrompidos; C: corte axial demonstrando elemento supranumerário maxilar irrompido; D: corte coronal demonstrando elemento supranumerário mandibular posterior; E: corte coronal demonstrando elemento supranumerário mandibular anterior; F: corte coronal demonstrando elemento supranumerário mandibular coronal e outro caudal, ambos fazendo íntima relação com canal medular.

Após análise, o procedimento cirúrgico para correção da alteração de número foi programado, sendo realizada previamente, uma investigação sobre possível infecção pelo COVID-19. Após resultados negativos, o procedimento cirúrgico foi programado em duas etapas: na primeira etapa foi realizada a extração de 05 elementos supranumerários e do terceiro molar cariado na região de mandíbula (Figura 3). O procedimento correu sem intercorrências, cumprindo todas as normas de paramentação, desparamentação e antissepsia. Na segunda etapa foi realizada a extração de 05 elementos supranumerários na região de maxila (Figura 4 ). 
Figura 3. Elementos supranumerários extraídos da mandíbula durante procedimento cirúrgico.

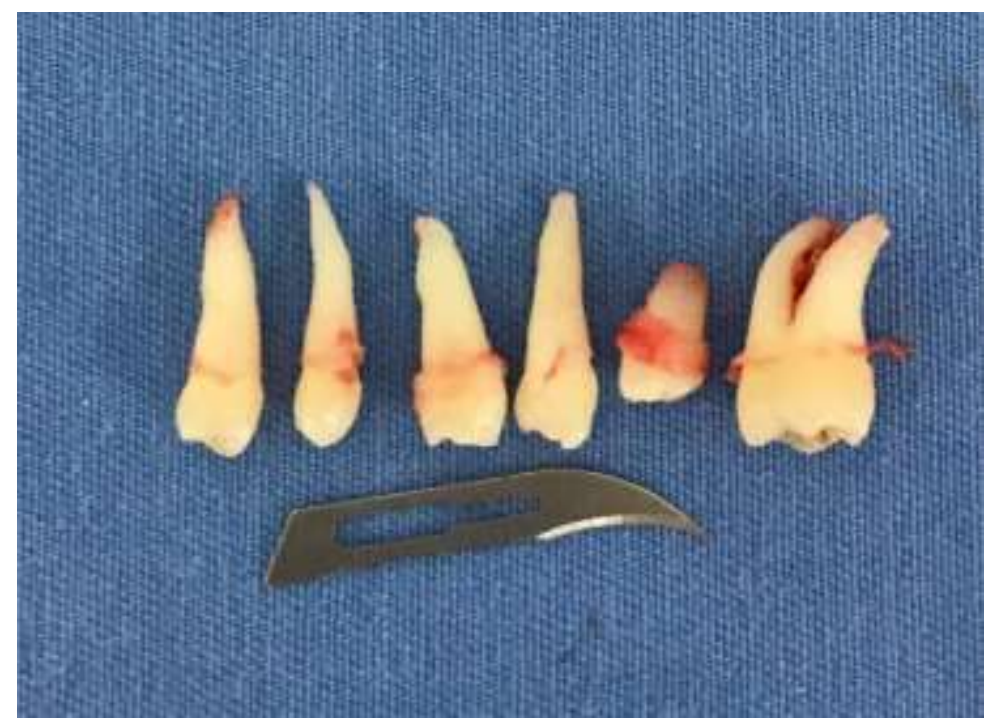

Fonte: Prontuário do paciente.

Figura 4. Elementos supranumerários extraídos da maxila durante procedimento cirúrgico.

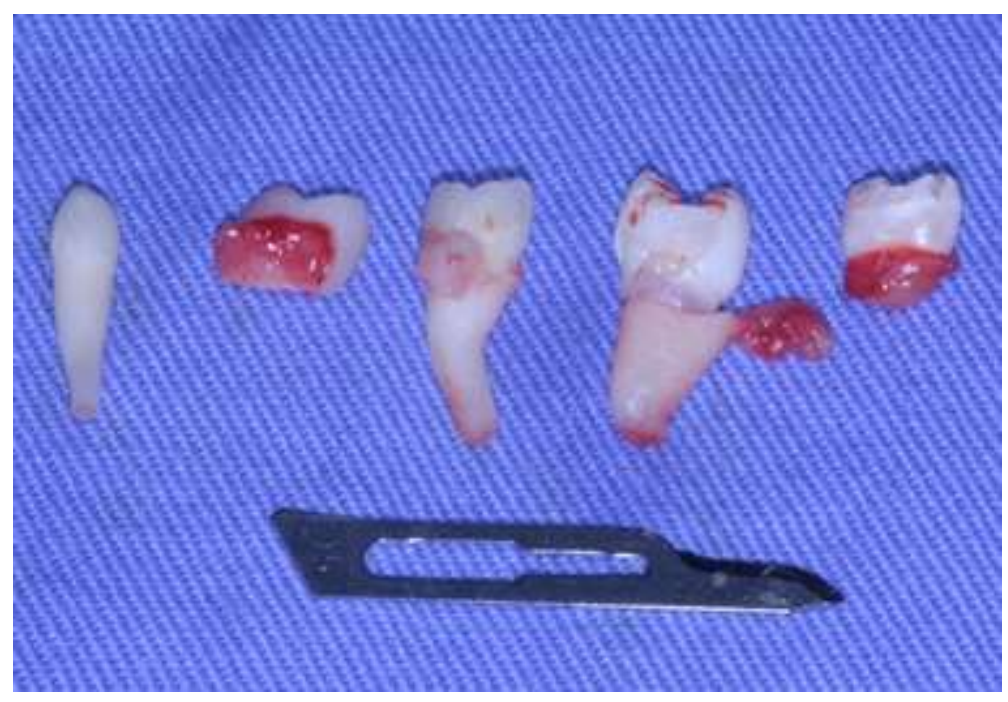

Fonte: Prontuário do paciente.

\subsection{Descrição do ato cirúrgico 1}

1- Realização de anestesia do nervo alveolar inferior, bucal e lingual do lado direito e esquerdo, antissepsia com clorexidina $2 \%$ extra bucal e clorexidina $0,12 \%$ intra bucal; seguida de realização de uma incisão sulcular com lâmina de bisturi $\mathrm{n}^{\circ} 15$, de pré-molar a pré-molar na região inferior, região da mandíbula (Figura 5);

2- Descolamento do periósteo utilizando descolador de Molt (Figura 6);

3- Remoção do primeiro dente: um supranumerário erupcionado do lado esquerdo, na região entre os pré-molares inferiores esquerdos. Foi realizada a luxação com alavanca reta e curva e auxílio de fórceps (Figura 7);

4- Curetagem do alvéolo com cureta de Lucas e irrigação com soro fisiológico estéril, seringa descartável estéril e agulha de irrigação;

5- Extração de outro dente erupcionado na mesma região do anterior, sendo realizado o mesmo procedimento supracitado (Figura 8); 
6- Extração de dois supranumerários impactados na região direita da mandíbula, próximo ao dente 45 (Figura 9);

7- Odontosecção necessária com broca Zecria com o contato de soro fisiológico estéril;

8- Retirada do próximo dente: um supranumerário na mesma região dos supranumerários impactados, através do mesmo processo dos anteriores (Figura 10);

9- Após extração dos 03 supranumerários do lado direito, novamente é feita a curetagem com cureta de Lucas e irrigação destas regiões (Figura 11);

10- Realizada exodontia do 38;

11- Retalho posicionado e suturado com fio de sutura tipo nylon 4.0 (Figura 12);

12- Ato sem intercorrências.

Figura 5. Registro do ato cirúrgico 1.

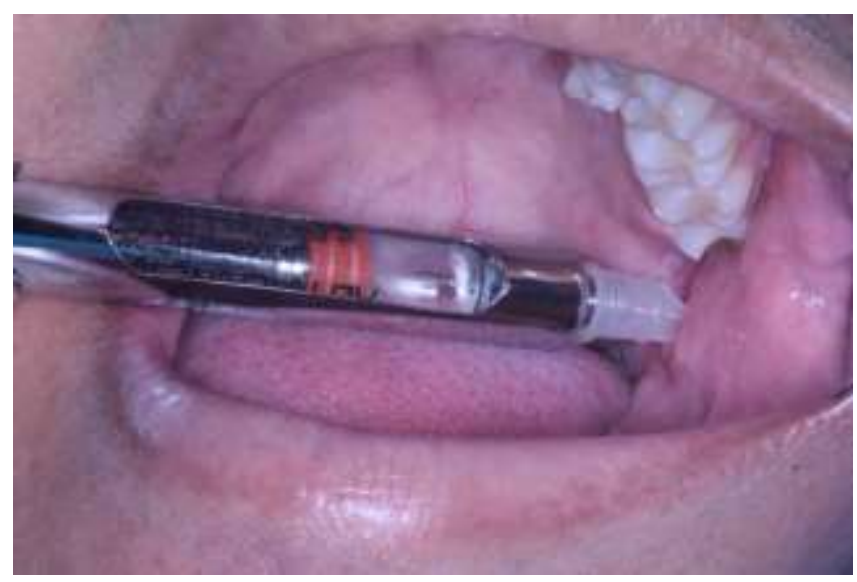

Fonte: Prontuário do paciente.

Figura 6. Registro do ato cirúrgico 1.

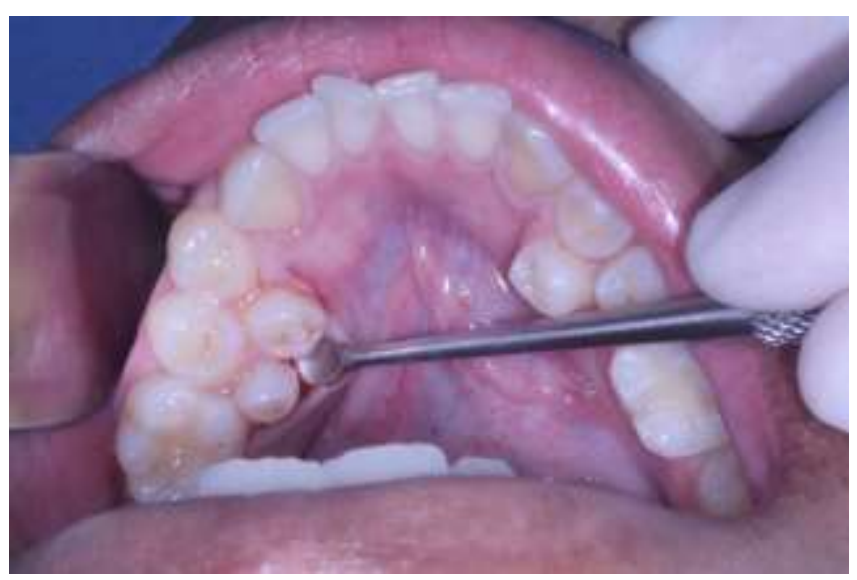

Fonte: Prontuário do paciente. 
Research, Society and Development, v. 10, n. 6, e31110615807, 2021

(CC BY 4.0) | ISSN 2525-3409 | DOI: http://dx.doi.org/10.33448/rsd-v10i6.15807

Figura 7. Registro do ato cirúrgico 1.

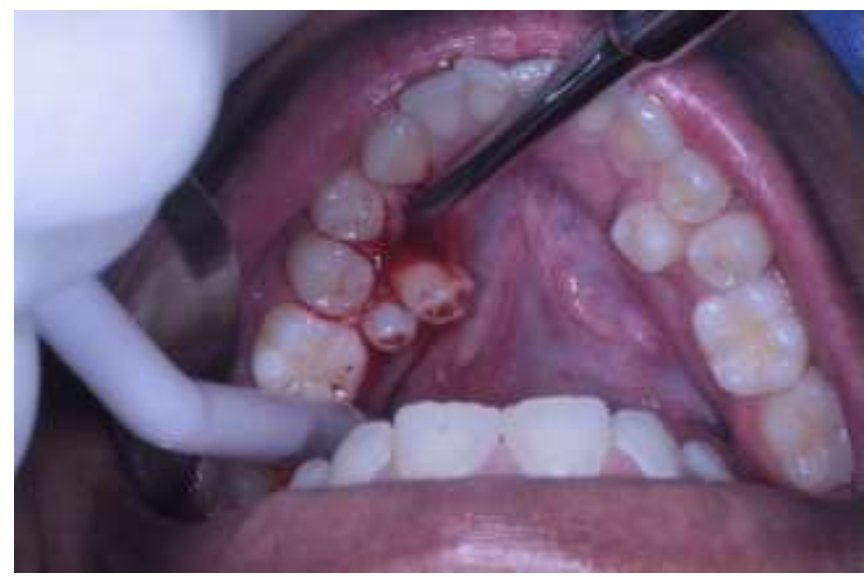

Fonte: Prontuário do paciente.

Figura 8. Registro do ato cirúrgico 1.

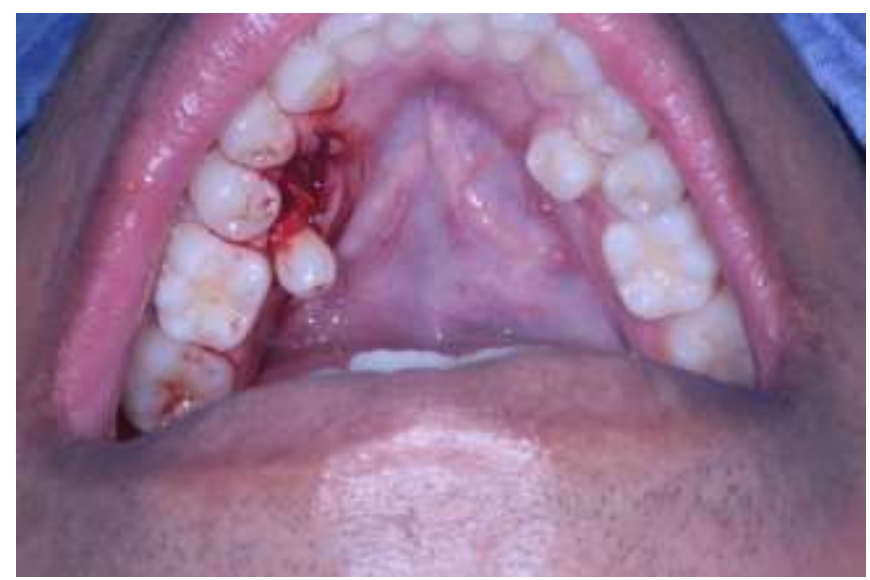

Fonte: Prontuário do paciente.

Figura 9. Registro do ato cirúrgico 1.

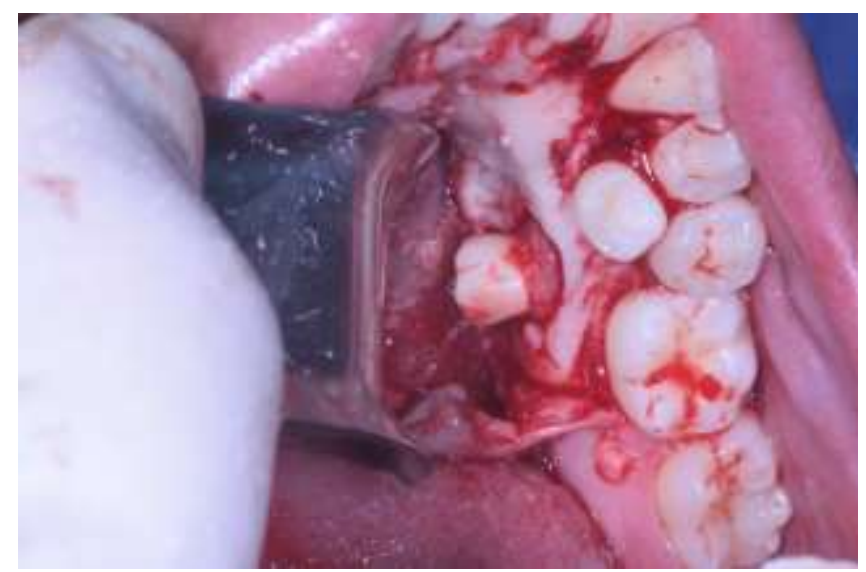

Fonte: Prontuário do paciente. 
Research, Society and Development, v. 10, n. 6, e31110615807, 2021

(CC BY 4.0) | ISSN 2525-3409 | DOI: http://dx.doi.org/10.33448/rsd-v10i6.15807

Figura 10. Registro do ato cirúrgico 1.

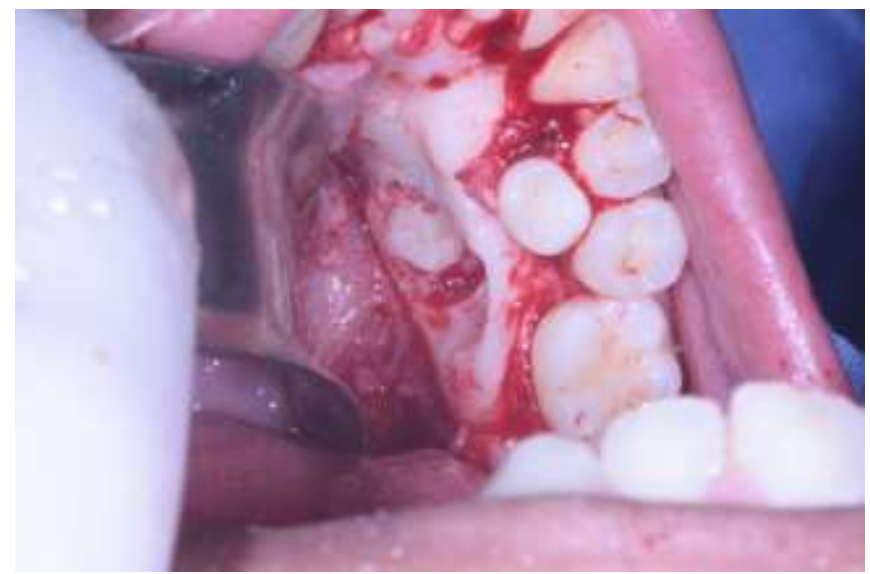

Fonte: Prontuário do paciente.

Figura 11. Registro do ato cirúrgico 1.

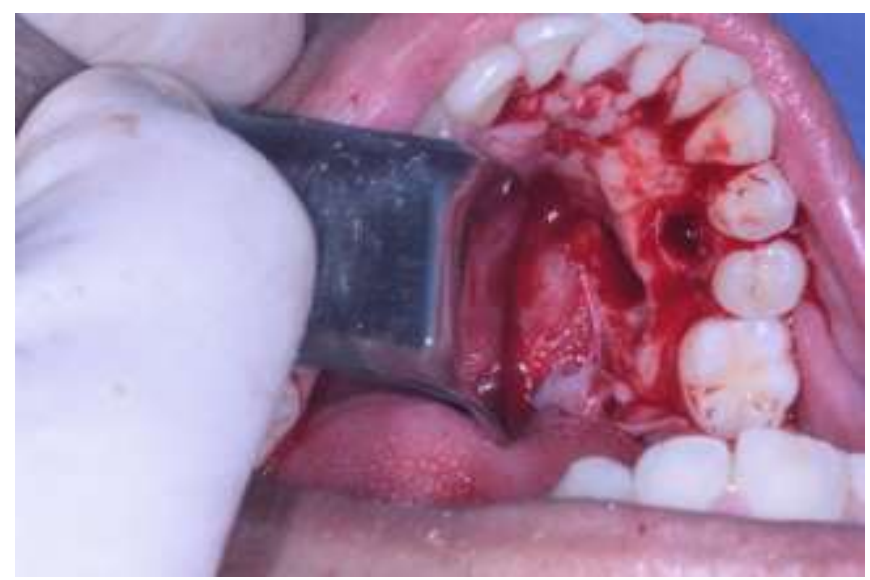

Fonte: Prontuário do paciente.

Figura 12. Registro do ato cirúrgico 2.

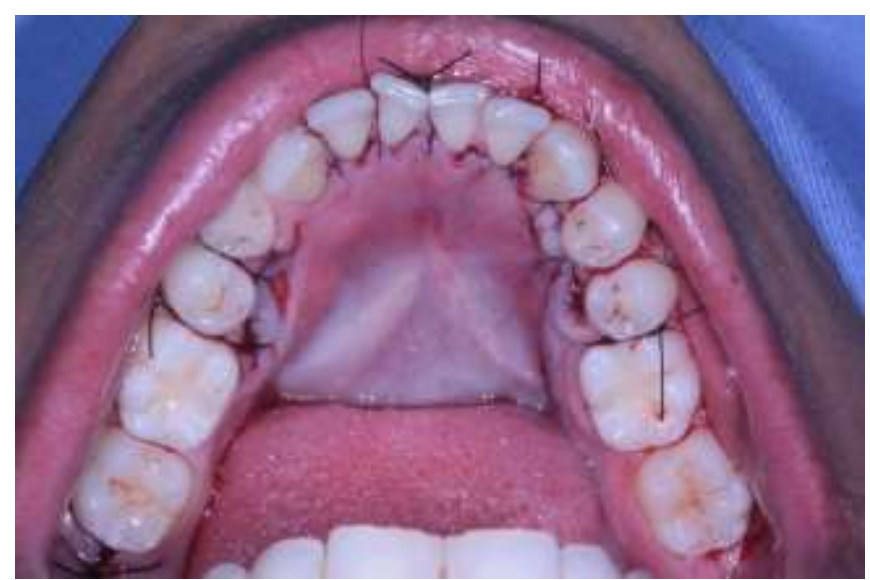

Fonte: Prontuário do paciente. 


\subsection{Descrição do ato cirúrgico 2}

1- Foram realizadas a antissepsia com clorexidina $2 \%$ extra bucal e $0,12 \%$ intrabucal, a anestesia do nervo alveolar superior médio e posterior do lado direito e esquerdo e feita a incisão sulcular com lâmina de bisturi $\mathrm{n}^{\circ}$ 15, de incisivos a molar do lado direito (Figura 13);

2- O primeiro dente a ser removido foi o dente incluso na região entre os pré-molares e o canino do lado direito. Fora feita odontosecção com broca Zecria e com o uso de alavancas (Figura 14);

3- Extração de outro dente incluso do lado esquerdo na região de pré-molares e canino (Figura 15);

4- Realizada curetagem do alvéolo com cureta de Lucas e irrigação com soro fisiológico esterilizado;

5- Realizado acesso por vestibular para ser possível a extração do terceiro dente incluso do lado esquerdo (Figura 16);

6- Retalho foi posicionado e suturado com fio de sutura tipo nylon 4.0;

7- Ato sem intercorrências.

Figura 13. Registro do ato cirúrgico 2.

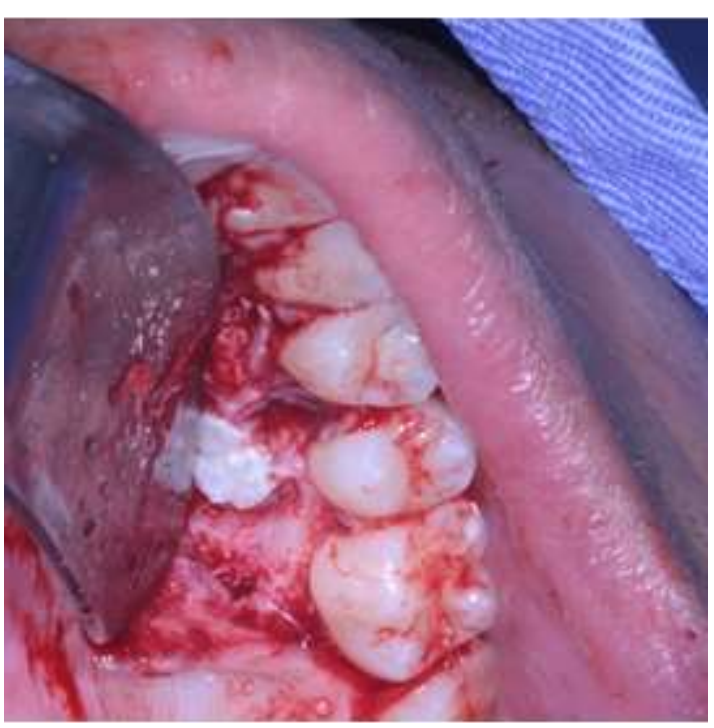

Fonte: Prontuário do paciente. 
Research, Society and Development, v. 10, n. 6, e31110615807, 2021

(CC BY 4.0) | ISSN 2525-3409 | DOI: http://dx.doi.org/10.33448/rsd-v10i6.15807

Figura 14. Registro do ato cirúrgico 2.

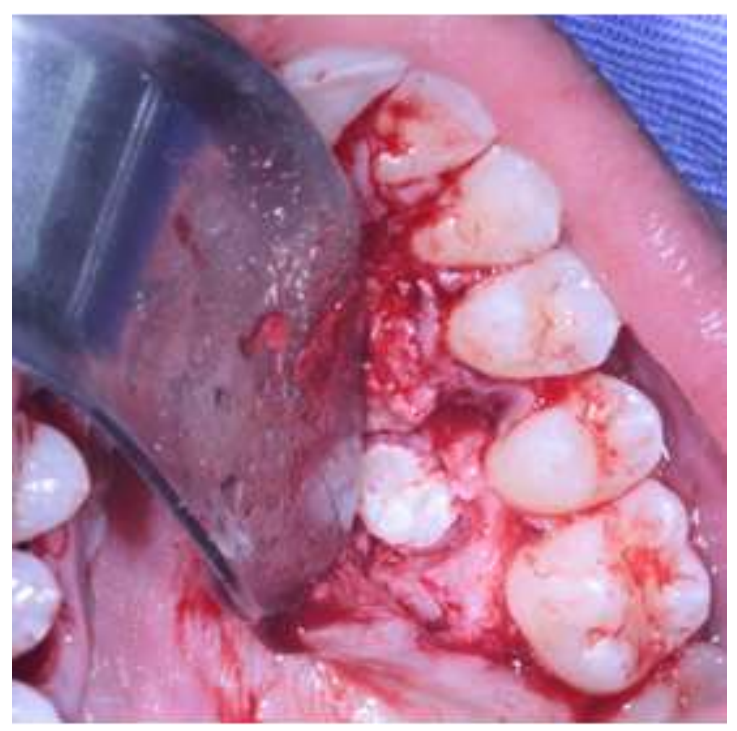

Fonte: Prontuário do paciente.

Figura 15. Registro do ato cirúrgico 2.

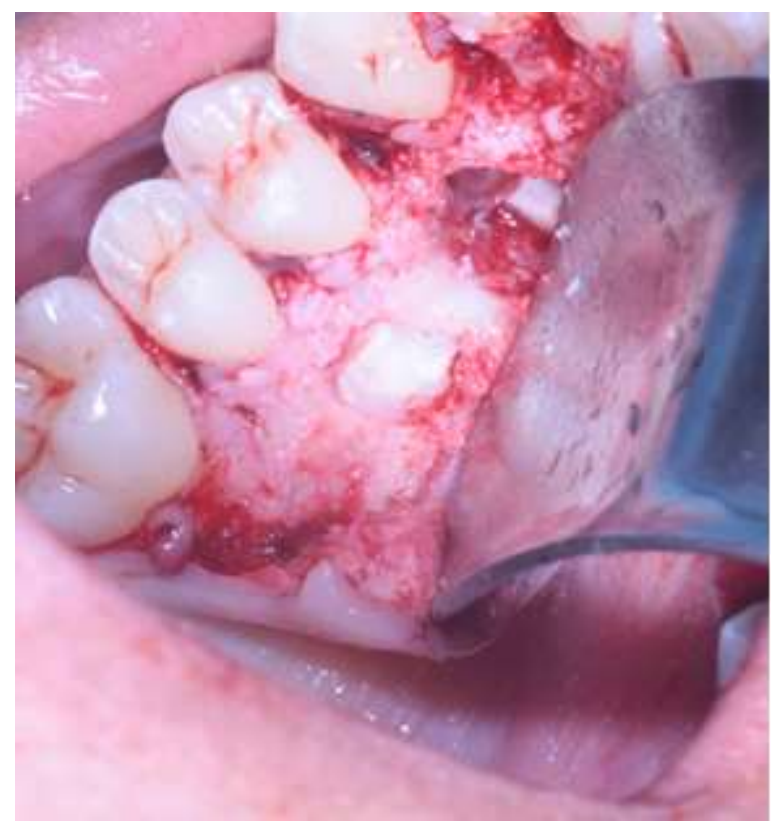

Fonte: Prontuário do paciente. 
Figura 16. Registro do ato cirúrgico 2.

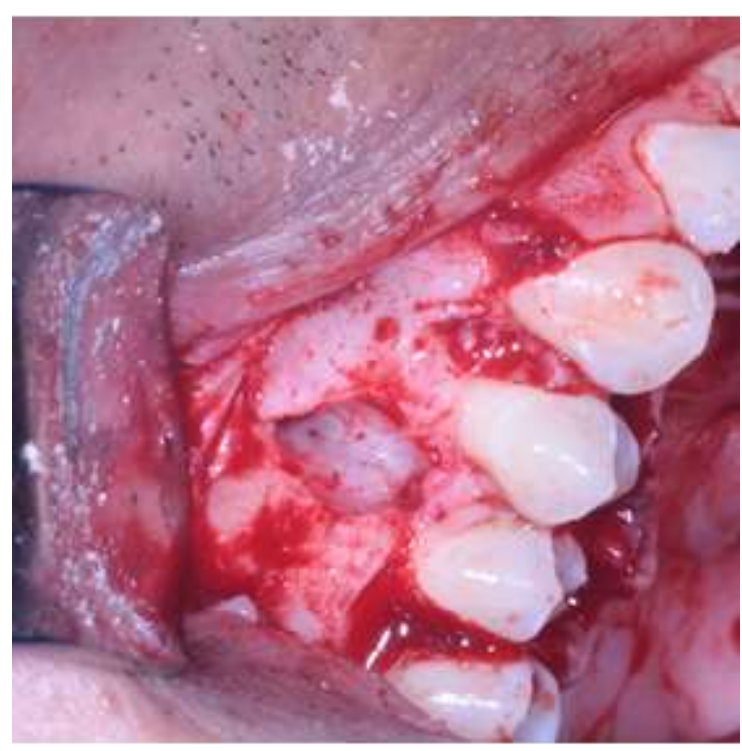

Fonte: Prontuário do paciente.

\section{Discussão}

Os dentes supranumerários são definidos na literatura como elementos dentários em excesso, ou seja, excedem o número de dentes normalmente existente nas arcadas. Podem ocorrer tanto na dentição decídua (com prevalência de 0.3-0.8\%), como na dentição permanente (0.1-3.8\%) 13. Podem apresentar-se morfologicamente malformados ou normais em tamanho e formato, em posição correta ou invertida e erupcionarem ou permanecerem impactados14. Neste paciente, as características dos dentes eram de dentes permanentes, os quais apresentavam aspecto de normalidade nos erupcionados e malformação nos dentes inclusos, o que vai de encontro à literatura.

Embora possa ocorrer em qualquer região dos maxilares, os supranumerários apresentam maior prevalência de ocorrência na maxila (de 8.2 a 10 vezes mais), especificamente na região anterior, em que recebem o nome de mesiodente13. Podem ser classificados quanto à sua morfologia, sendo denominados suplementares- quando apresentam a forma semelhante a um dente normal da maxila e da mandíbula; e rudimentares- quando mostram a forma anatômica diferente de um dente normal, podendo apresentar-se na forma conoide (forma de cone), tuberculados (forma de barril), ou na forma de odontomas15. Neste caso, a ocorrência foi similar em ambas às arcadas, embora a maxila tenha apresentado prevalência/ incidência nos dentes inclusos e mal formados, enquanto a mandíbula apresentou a maioria dos dentes em erupção e com formação completa.

Às vezes, a presença desse elemento extra não causa alterações patológicas. Porém, a ocorrência dessa anomalia costuma estar associada a problemas de estética, má oclusão e até formação de cistos e tumores 16.

O diagnóstico do dente supranumerário é clínico-radiográfico. Porém, o exame clínico e os exames complementares (radiografias e tomografias) auxiliam no correto diagnóstico e levam à conduta mais adequada para cada paciente. A experiência clínica profissional aliada à história clínica de antecedentes familiares devem ser considerados17. Como ocorreu no paciente acima, é comum que familiares de primeiro grau tenham também a mesma condição.

Recomenda-se a radiografia panorâmica, oclusal e periapical para auxiliar no diagnóstico e definir a posição vestíbulolingual quando impactado17. A radiográfica panorâmica é o exame de escolha para o diagnóstico precoce de alterações dentárias, pois é de fácil realização e aceitação dos pacientes: emite pouca radiação, permite a visualização de ambas as arcadas (as 
estruturas adjacentes em uma única imagem) e tem baixo custo se comparado à tomografia15. O diagnóstico precoce da condição minimiza problemas como a impacção dental, erupção atrasada ou erupção ectópica17.

A tomografia computadorizada é também um exame complementar muito indicado, pois auxilia a identificar com maior precisão a posição do elemento impactado. Porém, devido a seu alto custo, ainda não é um exame solicitado rotineiramente pelos profissionais. Neste caso, a tomografia computadorizada foi de fundamental importância na localização e extração destes dentes 15 .

A intervenção cirúrgica logo após o diagnóstico é indicada em grande parte dos casos para evitar futuras complicações e estabelecer um correto desenvolvimento da oclusão18. Por apresentar desvios na arcada dentária, alterações estéticas e fonéticas, a intervenção cirúrgica do caso relatado foi realizada logo após o diagnóstico, permitindo um prognóstico favorável e uma evolução sem intercorrências.

Quando não existem indícios de complicações, o acompanhamento e a observação periódica são recomendados para que o paciente tenha uma idade que lhe permita aceitar um procedimento mais invasivo e para prevenir possíveis danos às raízes dos dentes adjacentes19. Assim sendo, cada caso deve ser avaliado criteriosamente com a finalidade de prevenir complicações futuras.

De acordo com um estudo realizado por Canaves e Oliveira (2013), que realizaram uma busca na literatura sobre o impacto das alterações bucais na qualidade de vida dos adolescentes, foi relatado que as questões relacionadas à estética e à satisfação com a aparência, apresentam uma influência maior do que os fatores relacionados à função20. Assim, ter o sorriso desarmônico impacta diretamente na autoestima de uma pessoa, o que pode gerar danos em sua saúde mental, e até mesmo física21. Seguindo esta linha, o tratamento realizado no paciente do estudo foi de extrema importância para sua saúde, não só odontológica, mas também social e psicológica, pois o indivíduo se sentia demasiadamente infeliz com a estética do seu sorriso.

\section{Conclusão}

Em suma, após diagnóstico conclusivo e determinação cirúrgica, o paciente relatado recebeu o tratamento indicado para o seu caso. O tratamento foi realizado com sucesso através da remoção dos dentes supranumerários e da garantia da saúde bucal do paciente. Demonstrou-se assim, a pertinência do diagnóstico rápido, completo e da individualização da propedêutica nesses casos, a fim de evitar complicações futuras e melhorar a autoestima e sociabilização do paciente.

Apesar do nível atual de conhecimento acerca da conduta clínica em casos de supranumerários é de extrema importância a realização de novos estudos sobre o tema para que, dessa maneira os tratamentos se tornem cada vez mais seguros tanto para os cirurgiões dentistas como para os pacientes.

\section{Referências}

Agrawal, N. K. (2012). Dentigerous cyst in a child associated with multiple inverted supernumerary teeth: a rare occurrence. International journal of burns and trauma, 2(3), 171-173.

Alencar, N. V., Soares, B. M., Costa Santos, E. J., \& Silva, M. B. F. (2016). A importância da TCFC no diagnóstico e localização de dentes supranumerários. Revista Brasileira de Odontologia, 73(1), 55-69.

Anegundi, R. T., Tegginmani, V. S., Battepati, P., Tavargeri, A., Patil, S., Trasad, V., et al. (2014). Prevalence and characteristics of supernumerary teeth in a non-syndromic South Indian pediatric population. Journal of Indian Society of Pedodontics and Preventive Dentistry, 32(1), 1-9.

Araújo Junior J. L., Abreu N. M. R., Berutti L. M. (2021). Múltiplos dentes supranumerários em paciente não sindrômico. Arch health invest. 10(3), 501-504. Boehn A. Dental anomalies in harelip and cleft palate. Acta Odontol Scand. 1963. (21),1-109.

Dias, G. F., Hagedorn, H., Maffezzolli, M. D. L., Silva, F. D. F. D., \& Alves, F. B. T. (2019). Diagnóstico e tratamento de dentes supranumerários na clínica infantil-relato de caso. Revista CEFAC, 21(6), 1-8.. 
Hattab, F. N. (2014). Double talon cusps on supernumerary tooth fused to maxillary central incisor: review of literature and report of case. Journal of clinical and experimental dentistry, 6(4), e400.

Kim, K. D., Ruprecht, A., Jeon, K. J., \& Park, C. S. (2003). Personal computer-based three-dimensional computed tomographic images of the teeth for evaluating supernumerary or ectopically impacted teeth. The Angle Orthodontist, 73(5), 614-621.

Lodi, C. S., Rodrigues, A., \& Angeloni, B. P. (2017). Diagnóstico e tratamento de dente supranumerário incluso: relato de caso. Revista Funec CientíficaOdontologia, 1(1), 22-32.

Loreto, A. F. V., Kelmer, F., \& Oliveira, R. V. (2015). Supranumerário na região de mandíbula interferindo na oclusão: diagnóstico, planejamento e tratamento de um caso clínico. Revista uningá review, 21(1), 27-31.

Moura, W. L. D., Cravinhos, J. C. D. P., Moura, C. D. V., Freire, S. A. D. S., Monteiro, A. M. O., Pinheiro, S. D. A. et al. (2013). Prevalência de dentes supranumerários em pacientes atendidos no Hospital Universitário da UFPI: um estudo retrospectivo de cinco anos. Revista de Odontologia da UNESP, 42(3), $167-171$.

Nunes, K. M., Medeiros, M. V., Ceretta, L. B., Simões, P. W., Azambuja, F. G., Sônego, F. G. F. et al. (2017). Dente supranumerário: revisão bibliográfica e relato de caso clínico. Revista de Odontologia da Universidade Cidade de São Paulo, 27(1), 72-81.

Oliveira, D. C., Pereira, P. N., Ferreira, F. M., Paiva, S. M., \& Fraiz, F. C. (2013). Impacto relatado das alterações bucais na qualidade de vida de adolescentes: revisão sistemática. Pesquisa Brasileira em Odontopediatria e Clínica Integrada, 13(1), 123-129.

Pereira A. S. et al. (2018). Metodologia da pesquisa científica. UFSM

Primo, L. G., Wilhelm, R. S., \& Bastos, E. P. D. S. (1997). Frequency and characteristics of supernumerary teeth in Brazilian children: consequences and proposed treatments. Revista de Odontologia da Universidade de São Paulo, 11(4), 1-20.

Santos, M. D. N., Diniz, F. S., Mattos, J. V., Veloso, J. M. D. S. C., \& de Sá, R. C. (2019). Exodontia de mesiodens em palato: relato de caso. Archives of health investigation, 8(6), 296-299.

Shah, U. D., Patel, H., Patel, N., Ranadheer, E., \& Shoba, F. (2015). Interception in pursuit of exquisite aesthetics-a case series. Intern Journ. Of Adv. Research, 3(7), 590-598.

Silva A. B. L. (2020). Dentes supranumerários: uma revisão de literatura. TCC. Centro Universitario Unidade de Ensino Superior Dom Bosco, São Luís, MA, Brasil.

Silva, P. F. B., Hipólito, I. I., Vincentin, A., Goya, S., \& Junior, H. C. F. (2018). Múltiplos dentes supranumerários em paciente não sindrômico: revisão de literatura e apresentação de caso clínico. Revista Uningá, 55(S3), 211-220.

Stringhini Junior, E., Stang, B., \& Oliveira, L. B. (2015). Dentes supranumerários impactados: relato de caso clínico. Revista da Associacao Paulista de Cirurgioes Dentistas, 69(1), 89-94.

Sykaras, S. N. (1975). Mesiodens in primary and permanent dentitions: report of a case. Oral Surgery, Oral Medicine, Oral Pathology, 39(6), 870-874.

Tuna, E. B., Kurklu, E., Gencay, K., \& Ak, G. (2013). Clinical and radiological evaluation of inverse impaction of supernumerary teeth. Medicina oral, patologia oral y cirugia bucal, 18(4), e613.

Turner, C. (1877). Case of Supernumerary Upper Incisor Tooth. J Anat Physiol. 12(Pt 1):142-314. 